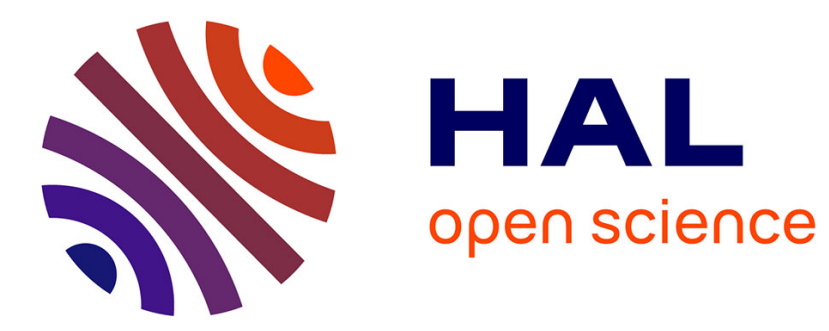

\title{
ANELASTIC RELAXATION IN NIOBIUM AND TANTALUM ANNEALED IN ULTRA HIGH VACUUM
}

\author{
F. Mazzolai
}

\section{- To cite this version:}

F. Mazzolai. ANELASTIC RELAXATION IN NIOBIUM AND TANTALUM ANNEALED IN ULTRA HIGH VACUUM. Journal de Physique Colloques, 1972, 33 (C6), pp.C6-163-C6-165. 10.1051/jphyscol:1972637 . jpa-00215155

\section{HAL Id: jpa-00215155 https://hal.science/jpa-00215155}

Submitted on 1 Jan 1972

HAL is a multi-disciplinary open access archive for the deposit and dissemination of scientific research documents, whether they are published or not. The documents may come from teaching and research institutions in France or abroad, or from public or private research centers.
L'archive ouverte pluridisciplinaire $\mathbf{H A L}$, est destinée au dépôt et à la diffusion de documents scientifiques de niveau recherche, publiés ou non, émanant des établissements d'enseignement et de recherche français ou étrangers, des laboratoires publics ou privés. 


\title{
ANELASTIC RELAXATION IN NIOBIUM AND TANTALUM ANNEALED IN ULTRA HIGH VACUUM
}

\author{
F. M. MAZZOLAI
}

\author{
CNR, Istituto di Acustica «O. M. Corbino », Via Cassia, 1216 Rome, Italy
}

\begin{abstract}
Résumé. - Des mesures de frottement interne effectuées sur du niobium et du tantale recuits à des températures élevées, ont montré l'existence d'un pic de frottement interne. Les valeurs de l'énergie d'activation et du temps limite sont $0,204 \mathrm{eV}$ et $2 \times 10^{-13} \mathrm{~s}$ dans le niobium et $0,26 \mathrm{eV}$ et $2 \times 10^{-13} \mathrm{~s}$ dans le tantale. On a trouvé que la hauteur du pic n'est pas sensible à la déformation plastique et à la teneur en hydrogène ou en deutérium. Une discussion sur les mécanismes possibles de ce pic est donnée.
\end{abstract}

Abstract. - An internal friction peak has been observed at low temperatures in tantalum and niobium annealed at high temperatures in ultra high vacuum. The activation energy and the limit relaxation time, as measured from the frequency dependence of the peak temperature, are found to be $0.204 \mathrm{eV}$ and $2 \times 10^{-13} \mathrm{~s}$ for niobium and $0.26 \mathrm{eV}$ and $2 \times 10^{-13} \mathrm{~s}$ for tantalum. The hydrogen and deuterium impurities as well as plastic deformation do not significantly affect the relaxation strength of the peak. A discussion of the possible structural mechanisms of the relaxation process has been presented.

1. Introduction. - Some years ago a low temperature internal friction peak was observed in well annealed platinum [1]. The peak height was found to increase as a result of repeated cold working and annealing treatments. On the basis of this observation it was argued that dislocations might be responsible for this anelastic relaxation process. However, the available experimental information did not allow a conclusive interpretation of this effect.

The present experiments were undertaken to check the existence of a similar internal friction peak in annealed niobium and tantalum. It is known that the content of gaseous impurities of niobium and tantalum can be lowered by means of anneals in ultra high vacuum. This, coupled with the significant effect of impurities on the internal friction of these metals, makes them an interesting subject of investigation.

2. Experimental. - The samples were cut from $99.9 \%$ pure niobium and tantalum supplied by Union Carbide Stellite Co. After machining, the specimens were annealed in an ultra high vacuum apparatus (Varian Assoc.). The oxygen content of the samples was estimated after this annealing treatment by measuring the low temperature side of the Snoek peak due to oxygen. The geometrical dimensions, the oxygen content and the thermal treatments subsequently undergone by the samples are described in tables I and II.

\section{TABLE I}

Characteristics and history of niobium samples

Dimensions

$\begin{array}{ccc}\text { Sample } & \begin{array}{c}\text { Diameter } \\ (\mathrm{mm})\end{array} & \begin{array}{c}\text { Thickness } \\ (\mathrm{mm})\end{array} \\ \overline{1} & \overline{25} & \overline{4.5} \\ 2 & 30 & 4.5\end{array}$

\section{Thermal treatments}

$\begin{array}{cccc}\begin{array}{c}\text { Temperature } \\ \left({ }^{\circ} \mathrm{C}\right)\end{array} & \begin{array}{c}\text { Time } \\ (\mathrm{min})\end{array} & \begin{array}{c}\text { Pressure } \\ \text { (torr) }\end{array} & Q_{\mathrm{M}}^{-1} \times 10^{5} \\ 1 \overline{950} & \overline{90} & 5 \times \overline{10} & \overline{1.3} \\ 1950 & 90 & 5 \times 10^{-7} & 2.05\end{array}$

TABLE II

Characteristics and history of tantalum samples

Dimensions Diameter Thickness

$\begin{array}{ccc}\text { Sample } & (\mathrm{mm}) & (\mathrm{mm}) \\ 1 & - & - \\ 2 & 30 & 4.6 \\ & 30 & 6.5\end{array}$

Thermal treatments

Temperature Time Pressure

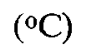

(a) $\overline{1} 800$

(b) 2200

(c) 2200

(a) 2200 $(\min )$

$\overline{60}$

60

180

180

(torr)
$3.7 \times 10^{-7}$
$1 \times 10^{-6}$
$1 \times 10^{-6}$
$1 \times 10^{-6}$

Oxygen content

(at. $\%$ )

$0 . \overline{045}$

0.070 
3. Results. - The dissipation coefficient $Q^{-1}$ of niobium annealed samples 1 and 2 is plotted in figure 1 as a function of temperature. Both samples

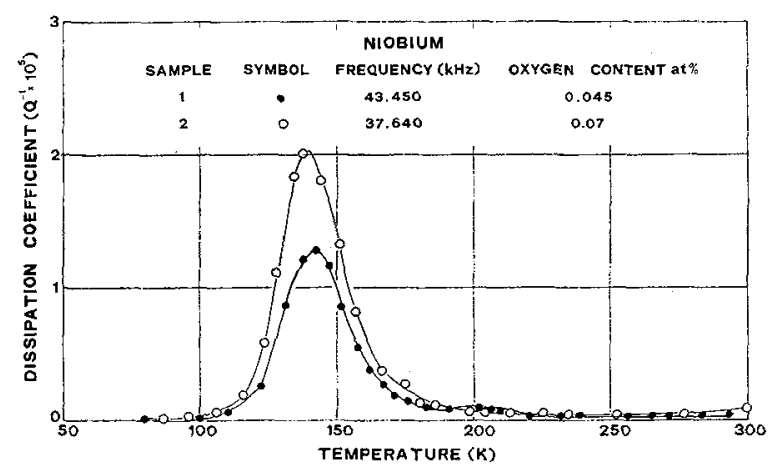

Fra. 1. - Internal friction of niobium samples 1 and 2 annealed at $1950^{\circ} \mathrm{C}$ for $90 \mathrm{mn}$.

display an exceedingly low background dissipation $\left(<6 \times 10^{-7}\right)$ and a well developed small peak near $140^{\circ} \mathrm{K}$. A similar peak is shown by tantalum specimen 2 near $175^{\circ} \mathrm{K}$, while only a bump is evident near $165^{\circ} \mathrm{K}$ in the curve of sample 1 (Fig. 2). A sequence

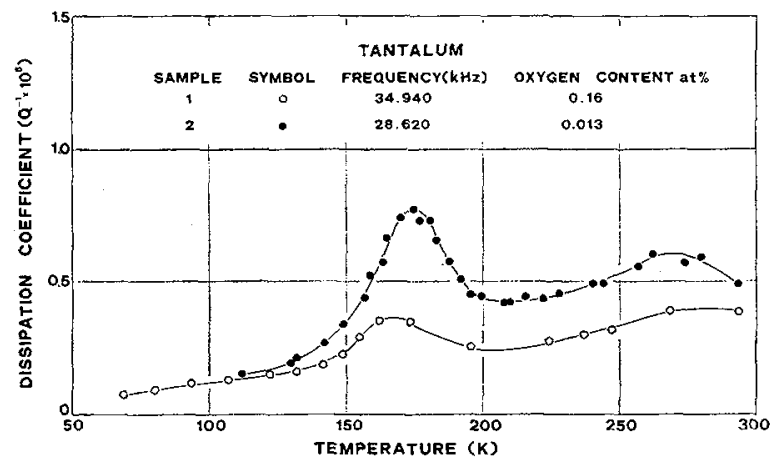

Fig. 2. - Internal friction of tantalum samples 1 and 2 annealed at $2200^{\circ} \mathrm{C}$ for $180 \mathrm{mn}$.

of plastic deformations by axial compression $\left(\varepsilon_{1}=0.50 \% ; \varepsilon_{2}=1.30 \% ; \varepsilon_{3}=2.50 \%\right.$ only introduced in previously annealed niobium sample 1 an increasing background dissipation $\left(<1.5 \times 10^{-5}\right)$, but it did not appreciably change the internal friction peak appearing near $140^{\circ} \mathrm{K}$.

After the measurement run reported in figure 1 niobium sample 2 was deuterium loaded at $245^{\circ} \mathrm{C}$ in a deuterium gas atmosphere of 0.8 torr. The deuterium content was found to be 0.05 at. $\%$. No significant changes were observed in the peak of figure 1 after this loading treatment, while an additional small peak $\left(Q_{\mathrm{M}}^{-1} \simeq 1 \times 10^{-6}\right)$ was introduced at $84^{\circ} \mathrm{K}\left(f_{84} o_{\mathrm{K}}=28.83 \mathrm{kHz}\right)$. This second peak is the one already reported by Schiller and Schneiders [2]. Substantial similar results were obtained in tantalum samples 1 and 2 after some electrolytical hydrogen loading treatments. The well known peak reported by Cannelli and Verdini [3] appeared simultaneously to the one of figure 2 , which did not show any evident change.

As it is seen in the Arrhenius plot of figure 3 the peak of figures 1 and 2 corresponds to a thermally

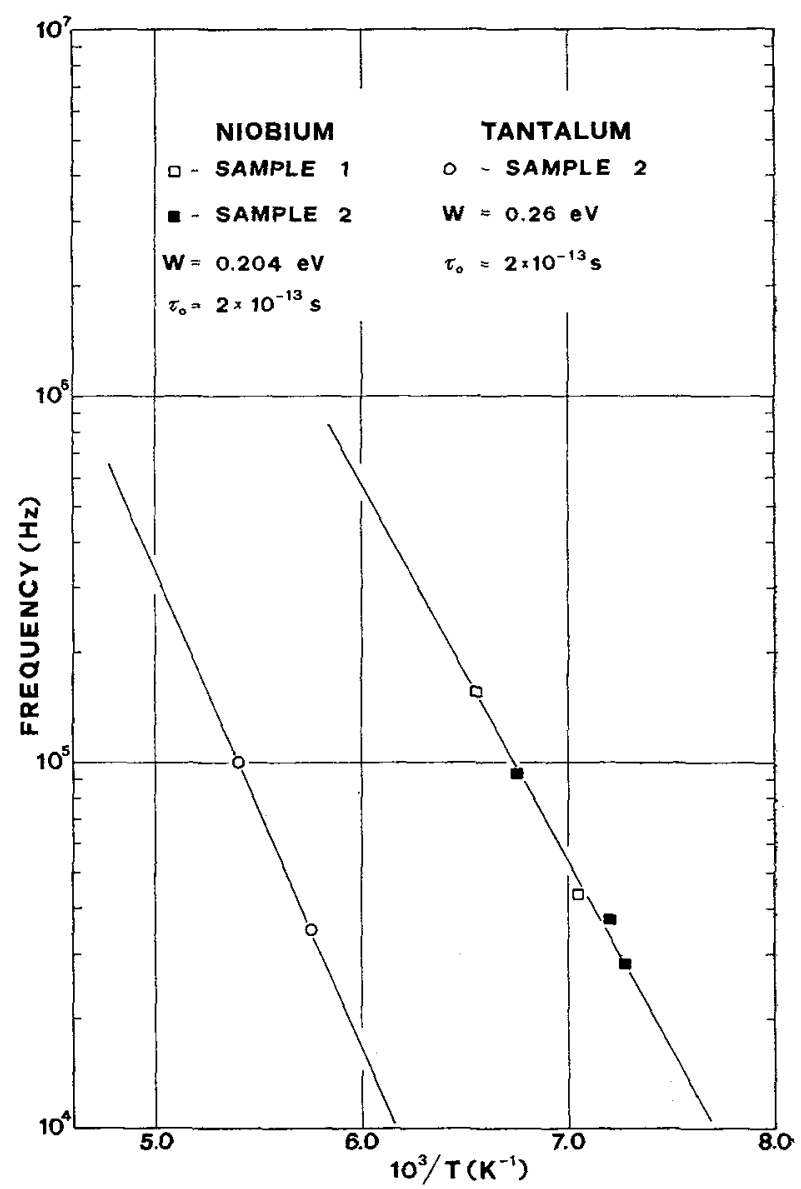

FIG. 3. - Frequency dependence of the peak temperature in niobium and tantalum.

activated relaxation process. In the case of niobium its activation energy $W$ and its limit relaxation time $\tau_{0}$ are $0.204 \mathrm{eV}$ and $2 \times 10^{-13} \mathrm{~s}$, respectively. Only indicative values can be deduced for tantalum from the two frequencies of figure 3 ; the straight line plotted in this figure gives $W=0.26 \mathrm{eV}$ and $\tau_{0}=2 \times 10^{-13} \mathrm{~s}$. A comparison between the theoretical Debye curve and the experimental ones of figure 1 shows that the relaxation effect has only one relaxation time. Measurements at different frequencies did not reveal any dependence of the peak height on the peak temperature.

4. Discussion. - A discussion of the peak reported in figures 1 and 2 can not leave out consideration hydrogen impurities. In fact the stress induced motion of hydrogen atoms gives rise to low temperature anelastic effects [2]-[4] with relaxation parameters not much different from the ones reported in this note. In figure 4 the relaxation time of our peak is compared with the one of relaxation processes $\mathrm{A}$ 


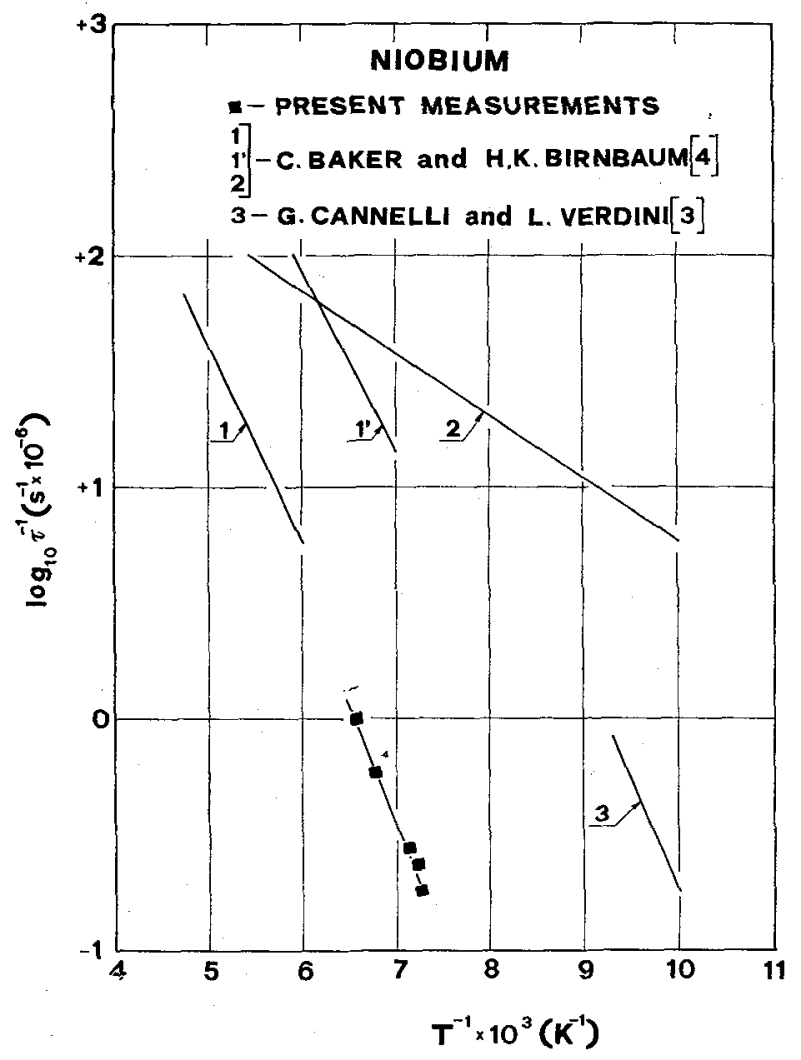

FIG. 4. - Relaxation time of the peak reported here and of the ones observed by Baker and Birnbaum and by Cannelli and Verdini in hydrogen loaded niobium. Straight lines 1 and $\mathbf{y}^{\prime}$ refer to the same process as measured at two different contents of oxygen and nitrogen (curve $1: 0.16$ at. $\% \mathrm{~N}$ and 1.2 at. $\% \mathrm{O}$; curve $1^{\prime}: 0.02$ at. $\% \mathrm{~N}$ and 0.06 at. $\% \mathrm{O}$ ).

(straight line 2) and $\mathrm{B}$ (straight lines 1 and $1^{\prime}$ ) recently observed by Baker and Birnbaum [4] and of that reported some years ago by Cannelli and Verdini [3] (straight line 3 ). Curve $1^{\prime}$ was obtained in a sample containing 0.16 at. $\% \mathrm{~N}$ and 1.2 at. $\% \mathrm{O}$, curve 1 in another one containing 0.02 at. $\% \mathrm{~N}$ and 0.06 at. $\% \mathrm{O}$. Taking into account the strong dependence of the relaxation time of process $B$ on oxygen and nitrogen contents (Fig. 4), consistency might be found for these two relaxation times. In spite of this a mechanism involving hydrogen atoms appears in contrast with some experimental observations. The insensitivity of the peak height to the hydrogen content can not be accounted for by assuming a Snoek type mechanism. On the other hand a dissipation model based on the reorientation of hydrogen atoms around some trapping site should predict a dependence of the relaxation strenght on temperature and hydrogen concentration, which has not been observed.

An identification of our peak with the one ( $\alpha$ peak) displayed in the same temperature range by coldworked niobium and tantalum seems to be ruled out by the following considerations. No plastic deformation was deliberately introduced in the annealed samples of figure 1 and 2 , which on the contrary were carefully handled to avoid fortuitous cold-work. Permanent deformations by axial compression were found not significantly affect the peak. Lastly, the very narrow relaxation time spectrum observed in these experiments seems not an usual feature of $\alpha$ peak.

We want focus attention to some similarities between the relaxation effect reported here and that one previously observed in annealed platinum [1]. Both peaks are introduced by high temperature anneals, they have quite similar relaxation strenght and appear in the same temperature range. So we conclude that the relaxation process observed in platinum annealed at high temperatures seems to have a counterpart in niobium and tantalum. These effects are so stable that a procedure for their elimination has not been discovered so far. This lack of knowledge about the experimental conditions for their cancelation and introduction prevents a clear understanding of their structural mechanisms.

Finally is to be noticed that the high sensitivity of today internal friction measurements reserves some interest even to the low temperature dissipation of recrystallized metals.

Acknowledgments. - The author is grateful to Professor M. Nuovo for useful discussions and he much appreciate G. Libriani who helped with the measurements taken.

\section{References}

[1] Coremberg J. et Mazzolai F. M., Solid State Commun 6 (1968) 1.

[2] Schiller P. et Schneiders A., Int. Conf. on Vacancies and Interstitials in Metals, Jülich, 2 (1968), 871.
[3] Cannelli G. et Verdini L., Ricerca Scient. 36 (1966) 98.

[4] Baker C. et Birnbaum H. K., Int. Meet. on Hydrogen in Metals, Jülich 1972, To be published. 